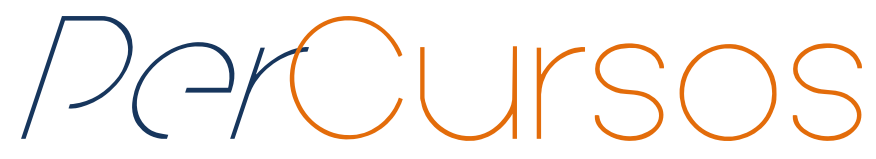

\title{
Ensino de história para alunos surdos: a construção de conhecimento histórico a partir de sequências didáticas
}

\section{Resumo}

O presente artigo tem por objetivo analisar a construção de um material didático (sequência didática) voltado para o ensino de tempo histórico para surdos. Nesta seara operamos conceitualmente com quatro campos do conhecimento, em especial: tempo histórico, surdez, linguagem e letramento. Entendendo como fundamental o respeito à cultura surda, sobretudo no que diz respeito à sua língua, a Língua Brasileira de Sinais Libras, todo o material histórico produzido foi construído em Libras, utilizando imagens e vídeos, materiais estes que, devido ao caráter visual, acreditamos serem os mais adequados para o ensino de História para crianças surdas. Tendo estas preocupações como ponto de partida, construímos uma sequência didática articulada em quatro eixos: ferramentas do tempo, medição temporal, distinção entre tempo histórico e tempo natural e, por fim, permanências e rupturas no tempo. Ressaltamos que neste material todo o conhecimento histórico foi construído em Libras, com o auxílio de uma intérprete, possibilitando o letramento destes alunos surdos. Este material é fruto de pesquisa empreendida no Mestrado Profissional em Ensino de História (PROFHISTORIA) da Universidade Federal Rural do Rio de Janeiro.

Palavras-chave: Ensino de História. Tempo Histórico. Surdez. Libras. Letramento.

\author{
Patrícia Bastos de Azevedo \\ Doutora em Educação pela \\ Universidade Federal do Rio de \\ Janeiro - UFRJ. Professora da \\ Universidade Federal Rural do \\ Rio de Janeiro - UFRRJ. \\ Brasil \\ patriciabazev@gmail.com
}

\section{Camilla Oliveira Mattos}

Mestra em Ensino de História pela Universidade Federal Rural do Rio de Janeiro - UFRRJ. Professora da rede estadual do Rio de Janeiro e do município de Seropédica. Brasil camilla.mattos@yahoo.com.br

\footnotetext{
Para citar este artigo:

AZEVEDO, Patrícia Bastos de; MATTOS, Camilla Oliveira. Ensino de história para alunos surdos: a construção de conhecimento histórico a partir de sequências didáticas. Revista PerCursos, Florianópolis, v. 18, n.38, p. 112 -133, set./dez. 2017.
}

\section{DOI: $\mathbf{1 0 . 5 9 6 5 / 1 9 8 4 7 2 4 6 1 8 3 8 2 0 1 7 1 1 2}$}

http://dx.doi.org/10.5965/1984724618382017112 


\title{
History teaching for deaf students: a construction of historical knowledge based on didactic sequences
}

\begin{abstract}
The objective of this study is the construction of a didactic material (sequence didactics) related to the teaching of historical time to the deaf. In this area, we operate conceptually four fields of knowledge in particular: historical time, deafness, language and literacy. In this sense, we understand how relevant it is the respect to the deaf culture, especially with regard to their language, the Brazilian Sign Language - Libras, all this historical material was constructed in Libras, using images and videos, materials that, due to the visual character, we believe to be the most suitable for the teaching of History to deaf children. Taking these concerns as a starting point, we have built a sequence didactics aimed to 6th grade deaf students, that is articulated in three axes: tools of the time, measurement of time and, finally, continuity and ruptures in time - theme built for two classes. We emphasize that all historical knowledge was built in Brazilian Sign Language (Libras), with the aid of an interpreter, enabling the literacy of the deaf students. This material is result of research carried out in the Professional Master's Degree in Teaching History (PROFHISTORIA) of the Federal Rural University of Rio de Janeiro.
\end{abstract}

Keywords: History Teaching. Historical Time. Deafness. Libras. Literacy. 


\section{Considerações iniciais}

Nas últimas décadas, no Brasil, particularmente sob o efeito das discussões sobre a necessidade de se repensar o papel e a importância da Língua Brasileira de Sinais (Libras) para as comunidades surdas, os debates em torno da educação de pessoas surdas ganharam espaço. As discussões se encaminharam no sentido de reconhecer a diferença linguística dos surdos e garantir que a Libras assumisse status de primeira língua (L1) para estes indivíduos, o que foi regulamentado em 2002, a partir da lei federal $\mathrm{n}^{\circ}$ 10.436. A partir desta lei, impõe-se a obrigatoriedade da Libras nos currículos dos cursos de formação de professores de nível médio, de licenciatura e de fonoaudiologia, legitimando-a como a língua oficial brasileira para as comunidades surdas.

Em 2005 esta lei foi regulamentada a partir do Decreto federal $n^{\circ}$ - 5.625, cuja importância define-se por explicitar mecanismos imperativos e ações públicas para a formação de profissionais para o ensino, interpretação e tradução da Língua Brasileira de Sinais, além de ações afirmativas para usuários da Libras e a expansão da língua. Ainda, no Capítulo V, define a formação necessária para o tradutor e intérprete de Libras, sendo necessário curso superior de Tradução e Interpretação, com habilitação em Libras Língua Portuguesa. Assim, a partir deste decreto, o modelo educacional bilíngue tornouse um direito adquirido pelas comunidades surdas, ocasionando o aumento de pesquisas e estudos acerca da inclusão de surdos em salas de aula regulares.

Esta produção acadêmica, entretanto, vem se mostrando desigual. O que se percebe é que as pesquisas acerca da educação e inclusão de indivíduos surdos concentram-se em determinadas áreas de conhecimento, sendo as áreas da Educação e Linguística responsáveis por mais dametade dos resultados em pesquisa empreendida no Banco de Teses da Coordenação de Aperfeiçoamento de Pessoal de Nível Superior (Capes). Nenhuma das dissertações e teses encontradas refere-se ao ensino de história para surdos.

Entendemos ser fundamental o surgimento de pesquisas e estudos dentro das diversas disciplinas curriculares, visto que cada disciplina possui especificidades que tornam seu conhecimento e, portanto, seu ensino, diferente dos demais. Assim, 
acreditamos ser premente que a história cumpra com sua responsabilidade compreendida no desafio de educar historicamente os alunos surdos, sem delegar esta tarefa aos campos de conhecimento que não são capazes de abordar com a profundidade teórica necessária a reflexão acerca da história ensinada.

Buscando romper com esta ausência de pesquisas em História, foi construída a dissertação "Sinais do Tempo: construção de significados de tempo histórico em Libras para alunos surdos em uma perspectiva de letramento em História", defendida em 2016, no Programa de Mestrado Profissional em Ensino de História (PROFHISTÓRIA) da Universidade Federal Rural do Rio de Janeiro (UFRRJ). Neste trabalho, procuramos promover o letramento em história de alunos surdos a partir do uso da Libras, focando os sentidos de tempo histórico - chão sobre o qual a história se constitui.

Nesta tarefa, priorizamos o uso de fontes imagéticas, considerando os aspectos de visualidade já contidos na Libras (CAMPELLO, 2008) e as indicações dos próprios alunos surdos (VERRI; ALEGRO, 2006). Assim nasceram as sequências didáticas - recursos pedagógicos de auxílio na construção do conhecimento histórico acerca do tempo.

Uma dificuldade corrente na educação de surdos, em diferentes disciplinas, mas particularmente no ensino de história, é a carência de conhecimentos prévios do alunado surdo. Devido à diferença linguística que marca a cultura surda, a inclusão destes indivíduos à cultura de massa, sobretudo aos principais meios de comunicação e informação, ocorre de forma bastante fragmentada e incompleta. Construídos em línguas orais, a maioria dos meios de informação - destacando-se os filmes, novelas, séries televisivas e programas de televisão -não possui maior preocupação quanto ao acesso do público surdo a estes conhecimentos que são partilhados, fazendo da tradução por intérprete de língua de sinais (ILS) ou das legendas as únicas ferramentas de inclusão do surdo.

Defendemos, no entanto, que a tradução e as legendas nãosãoos melhores recursos para este público, isto porque ambas partem da Língua Portuguesa na construção do conhecimento, excluindo ou tornando secundária a Libras. 
A Libras possui uma estrutura gramatical própria (QUADROS; KARNOPP, 2004), atendendo a todos os critérios linguísticos como léxico, sintaxe e possibilidades de geração de sentenças (STOKOE, 1960)Deste modo, ela é plenamente capaz de não apenas transmitir conhecimentos como também de construir significados para as mais diferentes ideias, sentimentos e sensações, pois é por meio da Libras que “(...) o surdo reflete e significa sua experiência de forma narrativa" (MATTOS, 2016, p. 98). Assim, o ideal para o acesso do surdo aos meios de comunicação e informação é que este conhecimento seja todo construído em Libras, e não apenas traduzido, o que causa o empobrecimento dos conteúdos, visto que muitos sinais não possuem correlatos em Libras. A tradução por intérprete de língua de sinais, embora consista em uma ferramenta importante na inclusão de surdos aos meios de informação, tem como princípio a construção do conhecimento em Língua Portuguesa.

O uso das legendas televisivas, entretanto, é ainda mais problemático. Neste caso, a tradução é feita da Língua Portuguesa falada para a Língua Portuguesa em sua modalidade escrita, o que constitui para os surdos grande dificuldade, uma vez que apenas a Língua Portuguesa é mobilizada, sendo a modalidade escrita apenas a segunda língua do sujeito surdo. Assim, é negado ao surdo o conhecimento a partir de sua primeira língua.

Esta dificuldade de acesso do público surdo aos meios de comunicação e informação impacta fortemente a escola, que atua paralelamente aos conhecimentos vernaculares (HAMILTON, 2002 apud ROJO, 2009) e deles se utiliza na construção do conhecimento escolar. Deste modo, é fundamental atentar para os conhecimentos prévios que os alunos carregam para a escola.

A relação entre os conhecimentos prévios do aluno surdo e a necessidade de se pensar novos materiais de apoio no ensino de história serão pontos focais na reflexão elaborada ao longo deste artigo. 


\section{Tempo histórico, linguagem e surdez}

É ofício do historiador tecer possibilidades de interpretação do passado ${ }^{\text {. Neste }}$ sentido, os fatos históricos são como matéria prima do historiador, que a partir deles promove sentidos às experiências passadas² ${ }^{2}$ Segundo Prost (2012):

A questão do historiador é formulada do presente em relação ao passado, incidindo sobre as origens, evolução e itinerários no tempo, identificados através das datas. A história faz-se a partir do tempo: um tempo complexo, construído e multifacetado. (PROST, 2012, p. 96)

Assim, Prost aborda que o tempo é socialmente forjado. Categoria tão complexa e, ainda assim, tão básica - o tempo -, ela é associada ao próprio conceito de história: a ação dos seres humanos no tempo. Datas, séculos, anos, cronologia, linha do tempo: pontos e representações do tempo, muitas vezes confundidos como o próprio, sem ainda significá-lo. É a história que, utilizando-se do tempo, promove-lhe sentido.

Em outras palavras, é a experiência sobre o tempo que promove sentido a ele. Sentido este que surge no movimento entre presente-passado e presente-futuro, ao que Koselleck chama espaço de experiência e horizonte de expectativa. Estas são categorias meta-históricas ${ }^{3}$, cuja importância reside na demarcação do protagonismo histórico do ser humano enquanto sujeito, fornecendo sentidos às suas experiências no tempo. Deste modo, embora a história tenha o passado como principal objeto deestudo, o ato de fazer história localiza-se no presente, onde ela é pensada e elaborada. As categorias metahistóricas formuladas por Koselleck, conforme dito anteriormente, caracterizam a própria proposição de uma história, definida como um arco de tensão entre o espaço de experiência e o horizonte de expectativa, em uma relação de interdependência, pois “não

\footnotetext{
${ }^{1}$ Consideramos história a ação das pessoas no tempo. Assim, é trabalho do historiador buscar fragmentos deste tempo, seja em um passado distante ou recente.

2 Sendo fruto de uma interpretação historiográfica, estas experiências passadas não são dadas, mas construídas a partir da narrativa histórica.

${ }^{3}$ Koselleck (2006), ao abordar as categorias meta-históricas, Ihes fornece um sentido não apenas histórico, mas também antropológico, pois ambas as categorias representam aquilo que origina todas as histórias.
} 
há expectativa sem experiência, não há experiência sem expectativa” (KOSELLECK, 2006, p. 307).

Neste sentido, é a partir da experiência do vivido que se formam os sentidos históricos. Segundo Ricoeur (1994) é na narrativa histórica que o passado ganha sentido, sendo este sentido direcionado à vida. Assim, a história, enquanto conhecimento produzido, deve ser satisfatória e útil à vida, de modo que é necessário conjugar lógica e vivido em uma interação dialética. Portanto, cabe à história não apenas produzir um conhecimento lógico, mas ensinar a pessoa a viver. A principal função da História seria oferecer aos seres humanos a consciência de sua presença e atuação no tempo, consciência esta estabelecida a partir da narrativa do vivido - entendido como experiência.

É na narrativa que atribuímos sentidos à experiência do tempo, em um movimento no qual "a língua conceptualiza o tempo de modo totalmente diferente da reflexão" (BENVENISTE, 1989, p. 70). Assim, a questão linguística merece especial atenção, uma vez que é a partir dela que promovemos sentidos à experiência subjetiva histórica.

Esta subjetividade do indivíduo, entretanto, decorre não de uma autoanálise, mas da distinção entre si e o outro. Segundo Benveniste (1991):

Em última análise, a temporalidade humana com todo seu aparato linguístico revela a subjetividade inerente ao próprio exercício da linguagem.

A linguagem é, pois, a possibilidade da subjetividade, pelo fato de conter sempre as formas linguísticas apropriadas à sua expressão; e o discurso provoca a emergência da subjetividade, pelo fato de consistir de instâncias discretas. A linguagem de algum modo propõe formas "vazias" das quais cada locutor em exercício de discurso se apropria e as quais refere à sua "pessoa", definindo-se ao mesmo tempo a si mesmo como eu e a um parceiro como tu. (BENVENISTE, 1991, p. 289)

Assim, o indivíduo apenas se reconhece como único em razão do outro, distinto de si. Esta diferenciação entre eu e tu, entretanto, decorre da atividade linguística, a partir do uso da palavra. Neste sentido, Bakhtin; Volochínov (2014) afirma: 
Na realidade, toda palavra comporta duas faces. Ela é determinada tanto pelo fato de que ela procede de alguém, como pelo fato de que se dirige para alguém. Ela constitui justamente o produto da interação do locutor e do ouvinte. Toda palavra serve de expressão a um em relação ao outro. Através da palavra, defino-me em relação ao outro, isto é, em última análise, em relação à coletividade. A palavra é uma espécie de ponte lançada entre mim e os outros. Se ela se apoia sobre mim numa extremidade, na outra apoia-se sobre o meu interlocutor. A palavra é território comum do locutor e do interlocutor. (BAKHTIN; VOLOCHÍNOV, 2014, p. 117)

Neste sentido, a linguística deve ser vista não como um conjunto de formas e regras estanques, mas na sua relação com os indivíduos. Segundo Bakhtin, a palavra deve ser entendida enquanto signo, caracterizado pela pluricidade que se dá no jogo da situação, em um contexto comunicativo. Diferencia-se, portanto, do sinal, cuja característica é a "comunicação puramente mecânica, nas linguagens técnicas e em todos os casos em que a resposta que provoca no interlocutor seja única, sem possibilidade de equívocos ou interpretações alternativas" (PONZIO, 2008, p. 90). Deste modo, podemos afirmar que o signo está para a interpretaçãoassim como o sinal está para o reconhecimento e a identificação.

Esta é uma questão especialmente cara à educação de surdos, visto que o aprendizado de uma segunda língua reflete esta discussão entre signo e sinal. $\mathrm{Na}$ assimilação de uma segunda língua - caso da Língua Portuguesa em sua modalidade escrita, para os surdos - a sinalidade e o reconhecimento são mais frequentes, pois ainda não houve o total aprendizado. Daí a necessidade de construir o conhecimento em Libras, língua na qual o surdo promove suas narrativas, articulando sentidos à sua experiência.Em sua primeira língua o sinal é apagado pois não se reconhece, se compreende.

Segundo Lodi, Harrison e Campos (2015, p.21-22), o ato de ler para os sujeitos surdos "implica reconhecimento vocabular, significação monossêmica da palavra e em pareamento termo-a-termo entre as palavras do português e da língua de sinais em detrimento da construção dos sentidos em circulação nos textos escritos". Neste caso, a 
leitura ocorre de forma mecânica, sem aprendizado ou compreensão, uma vez que o sinal não se tornou ainda um signo ideológico. Ainda, segundo as autoras:

Centrar o ensino apenas no aspecto gramatical não basta para a formação de sujeitos letrados, pois o acesso à escrita só será pleno quando ela for tratada e concebida como prática social de linguagem, cultural, social, histórica e ideologicamente determinada. (LODI, HARRISON, CAMPOS, 2015, p. 23)

Estas são questões fundamentais na emergência da reflexão sobre o ensino de história para sujeitos surdos. Letrar historicamente um aluno surdo significa dar sentido à sua experiência no tempo a partir de uma forma narrativa; narrativa esta produzida por ele em Libras, o que promove sentidos distintos daqueles produzidos em Língua Portuguesa.

\section{Letramento e ensino de história}

O ensino de história se constitui enquanto uma prática de letramento (AZEVEDO, 2011, 2013, 2015a, 2015b), na qual são prioritariamente estabelecidos eventos de oralidade, leitura e escrita. Pensar o letramento em história para surdos pressupõe, portanto, uma reformulação destas práticas de letramento, uma vez que este deve ser construído em Libras, primeira língua do surdo e língua na qual o sujeito surdo caracteriza e dá sentido às suas experiências.

Se, por um lado, compreendemos apenas a partir de signos, é preciso também esclarecer que estes signos estão dispostos na linguagem, em constante significação. Como no ensino de história para surdos estes conhecimentos devem ser construídos e dispostos em Libras, surgirão signos ideológicos distintos daqueles construídos em Língua Portuguesa.

Os enunciados produzidos na históriaensinada são permeados não apenas pelos saberes escolares, mas também por conhecimentos oriundos de fora do ambiente escolar, dentre os quais podemos destacar os valores familiares, práticas de leitura em 
família e produtos da mídia televisiva. Todos estes conhecimentos impactam fortemente o ensino de história, promovendo sentidos à históriaensinada.

Conforme vimos, a despeito do movimento de inserção de grupos marginalizados e oprimidos que vem ocorrendo nas últimas décadas no campo da pesquisa histórica, o ensino de História mantém-se alheio às necessidades de inclusão social do público surdo. Segundo Verri e Alegro:

Atualmente verifica-se uma contradição flagrante: enquanto a pesquisa histórica propõe retirar do esquecimento aqueles que não têm tido voz na história oficial, o ensino de História não tem se preparado para as possibilidades inexploradas que a relação com o "outro com necessidades educacionais especiais" pode propiciar no processo de ensino e aprendizagem. É evidente, naformação de professores dessa disciplina, a ausência de suporte para o trabalho com esses estudantes, particularmente com alunos surdos. (VERRI; ALEGRO, 2006, p. 98)

Assim sendo, é fundamental que a História se adapte a uma realidade plural no ensino, abrindo caminho para a real inclusão dos mais diversos grupos e demandas sociais. Pensar o ensino de história é em si um ato de cidadania e um engajamento na defesa da pluralidade de identidades. Deste modo, a inclusão do aluno surdo tem por premissa seu acesso a estas possibilidades oferecidas pela História.

A história ensinada tem como princípio a apresentação e construção de conceitos históricos bastante complexos, uma vez que são delineados em uma perspectiva espaçotemporal. Entretanto, esta prática exige que o aluno mobilize conhecimentos anteriores, construídos na maioria das vezes fora do ambiente escolar, em suas relações interpessoais e na interação com os diversos meios de comunicação.

No caso dos alunos surdos, no entanto, esta prática ocorre de maneira problemática, uma vez que suas relações interpessoais costumam ser restritas ao seio familiar, tendo seu acesso aos meios de comunicação dificultado devido à diferença linguística. Deste modo: 
Em sala de aula, na falta de referências anteriores para a construção de ideias, proposições, conceitos históricos, os estudantes tendem a aplicar o seu conhecimento mais geral na formulação dos novos conceitos. Assim ocorre uma ampliação de inferências, novos conceitos podem se constituir de forma cada vez mais pobre, dificultando a conexão entre eles e impedindo a atribuição designificados. É por isso que o conhecimento prévio do aluno e ascaracterísticas específicas do conhecimento histórico condicionarão em grande parte, o aprendizado. (VERRI; ALEGRO, 2006, p. 99/100)

Com suas relações sociais empobrecidas, o aluno surdo constrói seu conhecimento de maneira diferente dos ouvintes, uma vez que precisa traduzir um conhecimento construído em Língua Portuguesa para um novo conhecimento articulado em Libras. Deste modo, ao construir determinado conceito, o aluno precisa articular duas línguas bastante diversas - enquanto a Língua Portuguesa estrutura-se na oralidade, a Libras é marcadamente visuo-gestual - demandando grande esforço por parte do aluno. Segundo Lacerda, Santos e Caetano(2014, p. 186):

Para os surdos os conceitos são organizados em língua de sinais, que por ser uma língua visuogestual pode ser comparada a um filme, já que o enunciador enuncia por meio de imagens, compondo cenas que exploram a simultaneidade e a consecutividade de eventos ${ }^{4}$.

Deste modo, consideramos fundamental a construção de materiais didáticos voltados para o público surdo, que possibilitem a eles a construção do conhecimento em sua própria língua, a Libras. Neste sentido, detivemo-nos na confecção de sequências didáticas cujo tema é o tempo histórico. Voltado para turmas de $6^{\circ}$ ano do Ensino Fundamental do Instituto Nacional de Educação de Surdos (INES), o material foi todo produzido em Libras.

\footnotetext{
${ }^{4}$ Inferindo acerca desta possibilidade, trabalhamos com a hipótese de que o uso de imagens pode favorecer não apenas a percepção de simultaneidade e o movimento de consecutividade, mas também continuidades e rupturas.
} 


\section{Concepção e desenvolvimento das sequências didáticas}

Foram elaboradas quatro sequências didáticas como material de apoio para o professor no ensino de história para alunos surdos. Cada uma das sequências contém um eixo temático, segundo o qual foram articuladas reflexões históricas e propostas de atividade. Nestas, foram priorizadas as atividades com recursos imagéticos de ampla disponibilidade na internet, que receberam especial atenção epistemológica. Neste sentido, entendemos que a imagem é mais que uma ilustração, visto que carrega informações visuais sobre o mundo (AUMONT, 2012) formadas por sentidos simbólicos que tornam possível o conhecimento domundo a partir dela.

Em cada sequência didática é anexada uma cartilha, para uso exclusivo do professor, em que constam o tempo estimado para o desenvolvimento das atividades, os objetivos e conteúdos históricos que serão articulados em cada uma.

Ainda, cada sequência didática é composta por uma parte pedagógica dirigida ao professor, na qual são apresentados os objetivos, conteúdos, tempo estimado e material a ser utilizado em cada aula; uma parte explicativa, onde é explicado em Libras o conteúdo a ser trabalhado; e uma parte propositiva, em que constam as atividades pedagógicas propostas aos alunos surdos.

Foram selecionadas para exame neste artigo as sequências didáticas III e IV, apresentando os recursos visuais eo método utilizados para sua análise. Visando facilitar o acesso do público ouvinte, optamos por traduzir o conteúdo 5 para a Língua Portuguesa, resumindo as partes explicativa e propositiva.

\section{Sequência didática III}

Nesta sequência didática são exploradas as permanências e rupturas históricas, tendo como principais objetivos entender esses processos e identificá-los em fontes visuais.

\footnotetext{
${ }^{5}$ O conteúdo completo - inclusive com a versão em Libras - estará em breve disponível para acesso na CAPES.
} 
Em sua parte explicativa, são brevemente abordadas o que são fontes históricas e sua importância para o ofício do historiador. A partir destas informações são introduzidas as análises de mudança/ruptura e continuidade/permanência que são analisadas a partir de sequências de recursos visuais, como exemplificado a seguir:
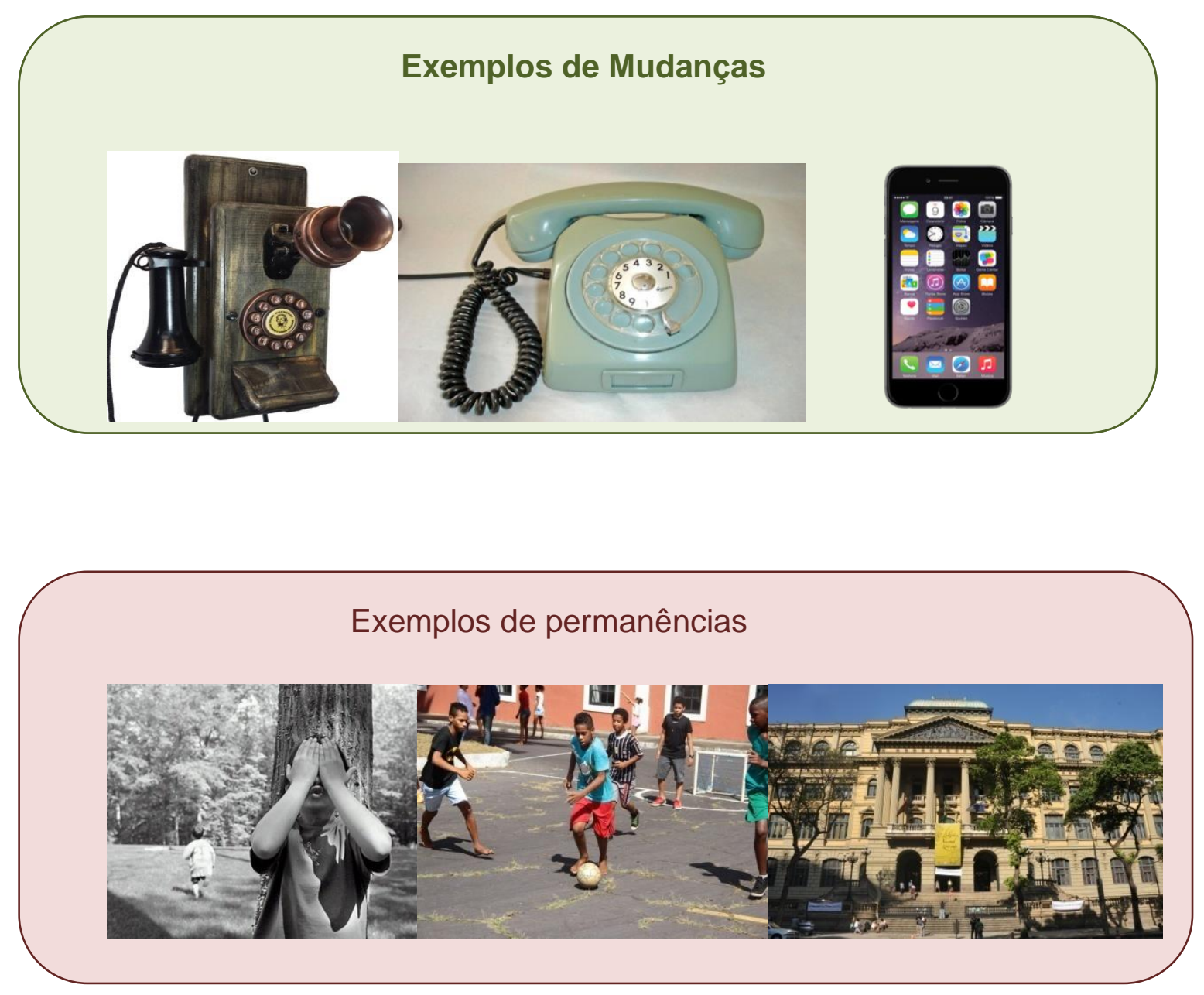

Seguindo no apelo às fontes visuais como principal recurso na construção do conhecimento do tempo histórico, é proposto que os alunos levem para sala de aula fotografias pessoais e que as disponham em ordem cronológica. É também importante incentivar a análise das fotografias pelos alunos, pedindo a eles o máximo possível de informações sobre cada foto. Estas informações devem ser descritas em Libras, mas, também escritas no caderno em Língua Portuguesa, de forma a auxiliar no letramento do aluno surdo em Português na modalidade escrita. 
Em outra atividade são apresentadas duas imagens da Praça Mauá, sendo a primeira nos anos 1930 e a segunda de 2014. Seguem as fotografias abaixo:

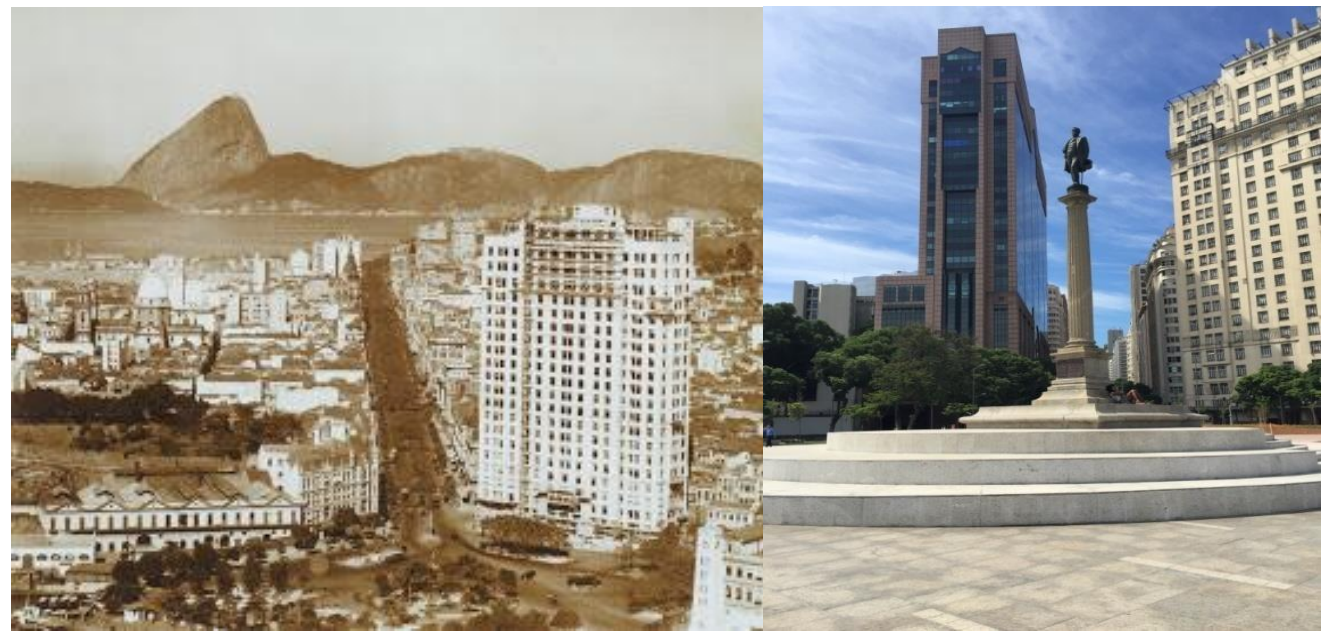

A partir da apresentação destas duas imagens, o aluno é inquerido acerca das permanências e mudanças ocorridas naquele espaço.

Outra questão semelhante é construída a partir da análise de quatro imagens que mostram ônibus na cidade do Rio de Janeiro. Seguem as imagens selecionadas:

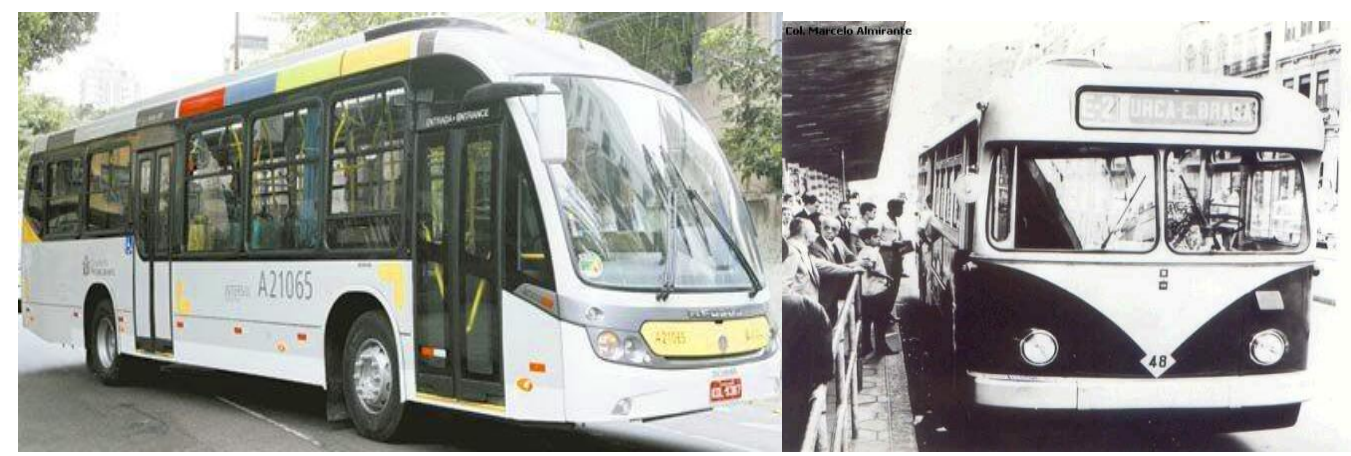



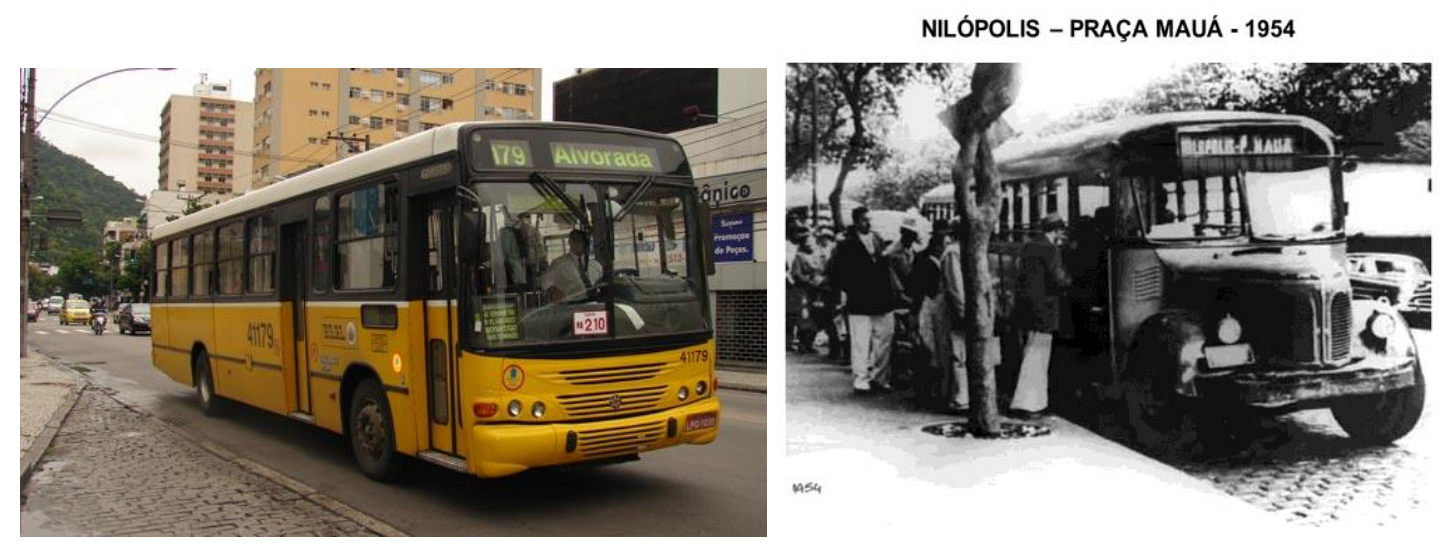

A partir da análise das imagens acima, primeiramente é pedido que os alunos organizem as imagens em ordem cronológica. Após, cada aluno é questionado sobre o que ele percebe ter mudado nos ônibus e o que permanece semelhante.

A partir destas atividades de reconhecimento e identificação espera-se que o aluno seja capaz de visualizar mudanças e continuidades históricas. Os desdobramentos destas atividades, entretanto, dependerão da ação do professor, uma vez que este é um material de apoio ao professor, não substituindo sua ação em sala de aula.

\section{Sequência didática IV}

A quarta e última sequência didática aprofunda as análises de permanências e rupturas históricas, mantendo os mesmos objetivos da sequência anterior. Nesta etapa, porém, são utilizadas, como recurso visual, imagens selecionadas do prédio do INES e aulas ali ministradas em diversos períodos históricos. A criação do Instituto data de 1856, e seu prédio atual ${ }^{6}$, de 1890 , de modo que o próprio espaço por ele ocupado possui uma história bastante rica.

A sequência didática IV aborda brevemente esta história do INES e, em seguida, por meio de imagens do prédio - a primeira, datada de 1926 e, a segunda, atual (2017)-

\footnotetext{
${ }^{6}$ Atualmente, o Instituto Nacional de Educação de Surdos encontra-se na Rua das Laranjeiras, 232, no bairro das Laranjeiras, cidade do Rio de Janeiro.
} 
compara as permanências e rupturas históricas ocorridas no espaço ocupado pelo Instituto, como observa-se a seguir:
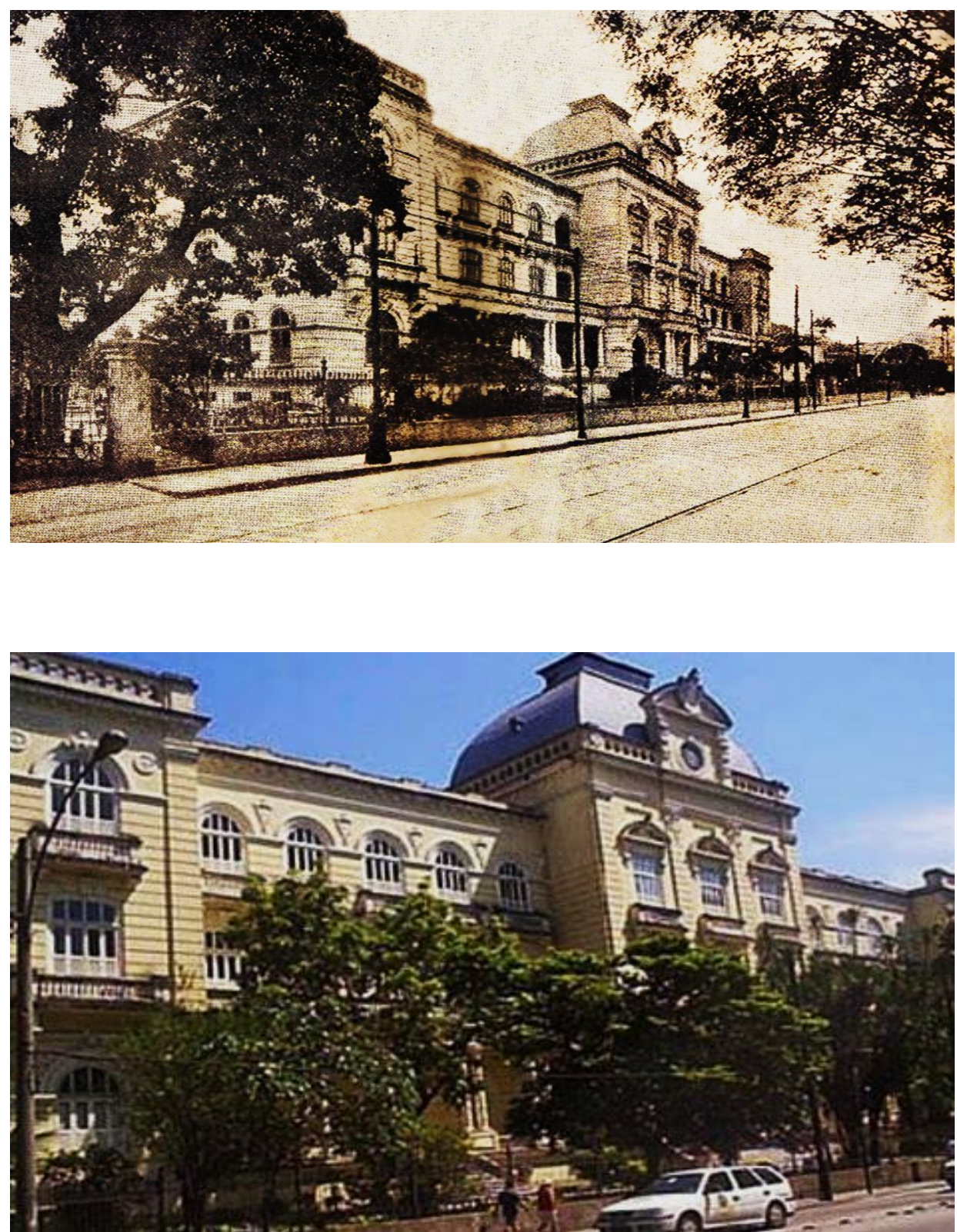

A partir destas explicações e comparações, propõe-se como atividade para os alunos a observação de uma fotografia que mostra uma aula de datilografia oferecida na década de 1930 no Instituto. A partir da imagem, apresentada a seguir, é pedido aos 
alunos que comparem a fotografia com as aulas atualmente oferecidas pelo INES, atentando para a disciplina lecionada e para a aparência da sala de aula.

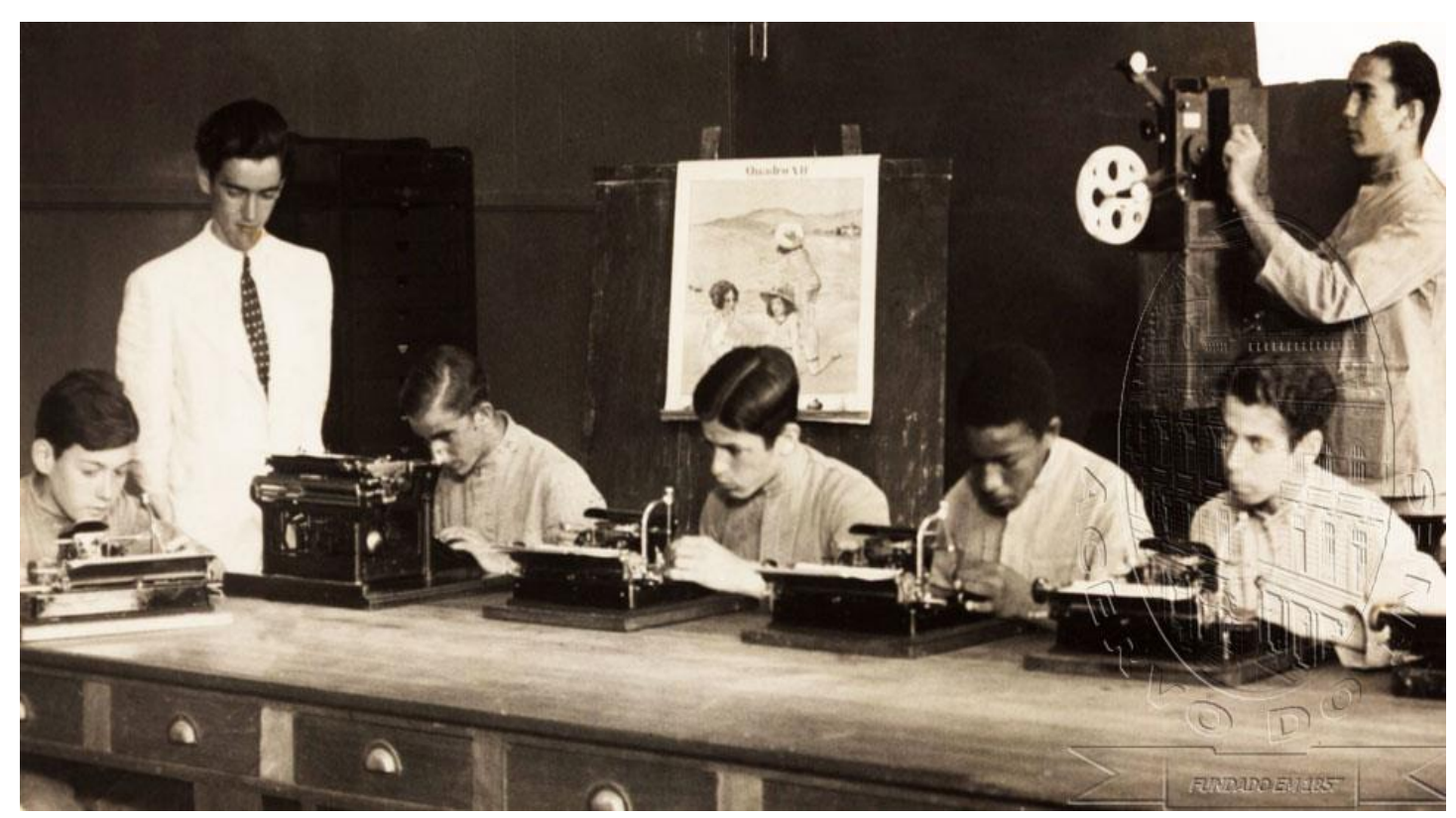

Outra atividade proposta pela sequência didática IV é a análise de um cartaz de 1926, no qual uma professora ensina sua aluna surda a falar. É pedido então, a partir da análise desta imagem, que o aluno compare o cartaz com as aulas oferecidas pelo INES, questionando-os se conhecem o método oralista ${ }^{7}$ e, em caso de resposta positiva, qual a sua opinião sobre o assunto.

\footnotetext{
${ }^{7}$ Em 1880, a partir da realização do II Congresso Internacional, em Milão, ficou definido o uso exclusivo do método oral, excluindo-se as línguas de sinais. Até 1960, este modelo imperou na educação de surdos, tendo resultados insatisfatórios, mostrando sujeitos apenas parcialmente alfabetizados após anos de escolarização.
} 


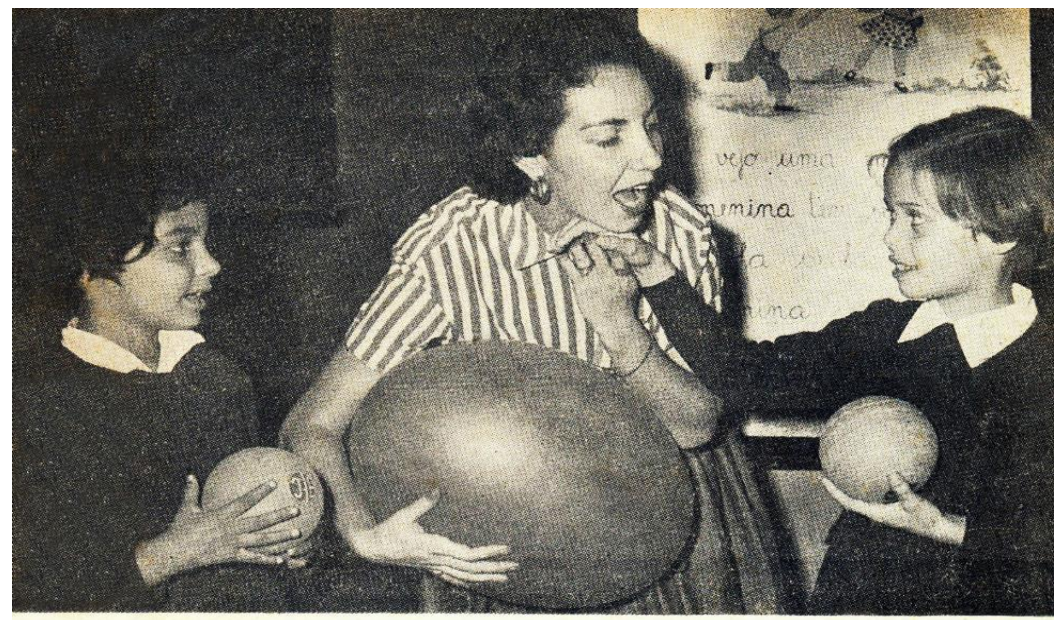

\section{F A L A !}

Órgão de assuntos técnicos e sociais relacionados com a educação dos deficientes da fala e da audição.

- Instituto Nacional de Surdos=Mudos -

2., $3 .^{\circ}$ ๑ $4 .^{\circ}$ TRIMESTRES

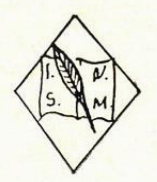

1956

\section{Considerações finais}

O ensino de história constitui-se como ato plural e híbrido, coadunando conhecimentos e saberes bastante específicos, dos quais se destacam: a) o conhecimento prévio do aluno; b) os conhecimentos academicamente produzidos e c) os saberes didático-pedagógicos envolvidos no ato de ensinar.Estas três esferas produzem o que podemos chamar história ensinada, concretizada na sala de aula, local este historicamente situado em um tempo-espaço.

No que se refere aos conhecimentos prévios do alunado surdo, verifica-se a dificuldade de acesso deste aos meios de difusão cultural, impactando na restrição de relações sociais importantes na construção do conhecimento. Entendendo o ensino de 
história enquanto uma prática de letramento, permeada por relações dialógicas constituídas a partir da linguagem, compreende-se que a restrição do público surdo aos principais meios de comunicação e mídias sociais atinge o conhecimento destes indivíduos que, ao longo de suas vidas, via de regra, possuíram poucos interlocutores de sua primeira língua - a Libras.

Verifica-se, ainda, a pouca produção sobre o ensino de história para surdos, de modo que resta aos professores de história o trabalho solitário, sem maiores reflexões e, em sua maioria, baseado em experiências próprias de tentativa e erro. O que sugerimos é a participação da história em meio às reflexões postas na área da Educação, encontrando questões em comum e dialogando com as demais áreas do conhecimento.

Assim, acreditamos que a história não deve se furtar à responsabilidade que the compreende no desafio de educar historicamente alunos surdos. Não é aceitável que a história feche os olhos para esta situação que se coloca, cedendo esta tarefa a campos do conhecimento que não são capazes de abordar com a profundidade necessária a reflexão acerca da história ensinada.

Visando romper com esta dificuldade e pensando o letramento em história para alunos surdo, foi aqui apresentado o processo de construção das sequências didáticas, material didático produzido como produto para o Programa de Mestrado Profissional em Ensino de História (PROFHISTÓRIA). Esperamos que as propostas contidas neste material possam auxiliar os professores de história na tarefa de letrar historicamente o aluno surdo, possibilitando a eles um novo olhar sobre a disciplina e sobre seu alunado.

Muitas são as dificuldades encontradas no caminho, sobretudo a inexistência de sinais correlatos aos conceitos históricos, dificultando a construção de significados junto aos alunos. Neste sentido, acreditamos que a construção de um glossário de sinais históricos, em processo semelhante aoque vem sendo produzido na área de ciências a partir do Projeto Surdos ${ }^{8}$, pode trazer resultados significativos para o ensino de história.

\footnotetext{
${ }^{8}$ O Projeto Surdos, promovido pela UFRJ e iniciado em 2005, tem como objetivo oferecer ao aluno surdo a possibilidade de ampliar a sua inserção no mercado de trabalho, através de uma formação técnica em Biociências.
} 
Neste sentido, novas preocupações surgiram ao longo desta pesquisa que, por questões metodológicas, não pudemos investigar mais profundamente. São questões tais como: a) quais os conhecimentos prévios que os alunos surdos utilizam para aprender história?; b) como incentivar a criação de materiais históricos adequados para surdos?;c) quais significados históricos os surdos articulam em suas experiências diárias? Acreditamos que estas são questões importantes que devem ser colocadas não apenas na área da Educação Especial, mas, também na história.

\section{Referências}

AUMONT, Jacques. A imagem. Campinas: Papirus, 2012.

AZEVEDO, Patrícia Bastos. História ensinada: produção de sentidos em práticas de letramento. Rio de Janeiro, 2011. Tese (Doutorado em Educação) - UFRJ, 2011.

AZEVEDO, Patrícia Bastos. História ensinada: práticas de letramento e produção de sentido. Educação: Teoria e Prática, Rio Claro, v. 23, n. 44, p. 24-45,Set./Dez. 2013.

AZEVEDO, Patrícia Bastos . Ensino de história, história, historiografia e produção de sentido em práticas de letramento. In: ROCHA, Helenice; MAGALHÃES, Marcelo; GONTIJO, Rebeca. $O$ ensino de história em questão: cultura histórica, usos do passado. Rio de Janeiro: FGV Editora, 2015a.

AZEVEDO, Patrícia Bastos. História ensinada e Dialogismo: prática de letramento o $6^{\circ}$ ano do Ensino Fundamental. Revista História Hoje, v.4, n. 8,p. 57-80, 2015 b.

AZEVEDO, Patrícia Bastos; MONTEIRO, Ana Maria Ferreira da Costa. A sala de aula e a produção de sentido em práticas de letramento na história ensinada. Práxis Educativa, Ponta Grossa, v. 8, n. 2, p. 559-580, Jul./Dez. 2013.

BAKHTIN, Mikhail; VOLOCHÍNOV,Valentin N. Marxismo e filosofia da linguagem: problemas fundamentais do método sociológico da linguagem. 16.ed. São Paulo: Hucitec, 2014.

BENVENISTE, Émile. Problemas de lingüística geral I. $3^{\text {a }}$ ed. Campinas: Pontes, 1991.

BENVENISTE, Émile. Problemas de lingüística geral II. Campinas: Pontes, 1989. 
CAMPELLO, Ana Regina. Aspectos da visualidade na educação de surdos. Tese (Doutorado em Educação) - UFSC, 2008.

KOSELLECK, Reinhart. Futuro passado: contribuição à semântica dos tempos históricos. Rio de Janeiro: Contraponto: Ed. PUC-Rio, 2006.

LACERDA, Cristina; Santos, Lara; CAETANO, Juliana. Estratégias metodológicas para o ensino de alunos surdos. In: LACERDA, Cristina; SANTOS, Lara. Tenho um aluno surdo, e agora? Introdução à Libras e educação de surdos. São Carlos: EdUFSCar, 2014. Pp. 185-201.

LODI, Ana Cláudia; HARRISON, Kathryn Marie; CAMPOS, Sandra Regina. Letramento e surdez: um olhar sobre as particularidades do contexto educacional. In: LODI, Ana Cláudia; MÉLO, Ana Dorziat; SANTOS, Juliana. Letramento, bilinguismo e educação de surdos. 2.ed. Porto Alegre: Mediação,2015, p. 11- 25.

MATTOS, Camilla. Sinais do tempo: construção de significados de tempo hitórico em Libras para alunos surdos em uma perspectiva de letramento em história. Rio de Janeiro, 2016. Dissertação (Mestrado em Ensino de História) - UFRRJ, 2016.

PONZIO, Augusto. A revolução bakhtiniana. São Paulo: Contexto, 2008.

PROST, Antoine. Doze lições sobre a história. 2. ed. Belo Horizonte: Autêntica Editora, 2012.

QUADROS, Ronice; KARNOPP, Lodenir. Língua de Sinais Brasileira: estudos lingüísticos. Porto Alegre: Artmed, 2004.

RICOEUR, Paul. Tempo e narrativa (tomo 1). Campinas: Papirus, 1994.

ROJO, Roxane. Letramentos múltiplos, escola e inclusão social. São Paulo: Parábola Editorial, 2009.

STOKOE, Willian. Sign language structure: an outline of the visual communication systems of the american deaf. University of Buffalo Press, New York, 1960.

VERRI, Célia Regina; ALEGRO, Regina Célia. Anotações sobre o processo de ensino e aprendizagem de história para alunos surdos. Práxis Educacional. Vitória da Conquista, n. 2, p. 7-114, 2006. 
Ensino de história para alunos surdos: a construção de conhecimento histórico a partir de sequências

didáticas

Patrícia Bastos de Azevedo, Camilla Oliveira Mattos

Recebido em: 30/06/2017

Aprovado em: 06/12/2017

Universidade do Estado de Santa Catarina - UDESC

Centro de Ciências Humanas e da Educação - FAED

Revista PerCursos

Volume 18 - Número 38 - Ano 2017

revistapercursos@gmail.com 